\title{
O Conhecimento Tradicional e o Ensino de Ciências: uma proposta de ensinar Biologia Vegetal
}

\author{
Traditional Knowledge and Science Teaching: a proposal to teach \\ Plant Biology
}

Lívia Fernandes dos Santos ${ }^{1}$

1 Mestre no Ensino de Ciências e Matemática, Instituto Federal de Educação, Ciência e Tecnologia do Acre - IFAC, Rio Branco, Acre, Brasil - livia.santos@ifac.edu.br/ https://orcid.org/0000-0002-2181-7760

Recebido em Maio/2019. Publicado em Agosto/2020

\author{
Palavras-chave: \\ Conhecimento \\ tradicional. Ensino. \\ Biologia.
}

\section{Keywords:}

Traditional knowledge. Teaching. Biology.
RESUMO: Este artigo relata a motivação e as etapas para elaboração de um produto educacional que foi elaborado durante a pesquisa desenvolvida a partir do Programa de Mestrado no Ensino de Ciências e Matemática ofertado pela Universidade Federal do Acre - UFAC, com a comunidade Rio Branco que ocupa o Seringal floresta da Resex Chico Mendes, localizada no município de Xapuri/AC. A investigação surgiu do interesse em conhecer a diversidade vegetal presente na comunidade tradicional e assim propor ensinar os conhecimentos científicos sobre esse tema em aproximação com os conhecimentos da comunidade, permitindo, assim, o diálogo de saberes. A troca de conhecimento ocorreu por meio da vivência das experiências da comunidade com os vegetais e da descrição de eventos que ocorrem no cotidiano da vida de um grupo. Com este contato foi possível ensinar ciências na Escola Rural União, frequentada pelos moradores da Resex. Para tal foi executado um plano de ensino com envolvimento e participação dos estudantes sob a perspectiva problematizadora, trabalhando de forma contextualizada com os saberes tradicionais sobre os vegetais. Assim o plano de ensino final intitulado "Aprendendo com as Plantas do dia a dia" tem caráter de formação a fím de contribuir como ferramenta pedagógica para os professores ensinar biologia vegetal de forma contextualizada e em aproximação com os conhecimentos das populações da Floresta.

ABSTRACT: This article reports the motivation and the steps for the elaboration of an educational product that was elaborated during the research developed from the Master's Program in Science and Mathematics Teaching offered by the Federal University of Acre - UFAC, with the Rio Branco community that occupies the Resex forest rubber Chico Mendes, located in the municipality of Xapuri / AC. The investigation arose from the interest in knowing the plant diversity present in the traditional community and, thus, proposing to teach scientific knowledge on this topic in approximation with the knowledge of the community, thus allowing the dialogue of knowledge. The exchange of knowledge occurred through the experience of the community's experiences with vegetables and the description of events that occur in the daily life of a group. With this contact it was possible to teach science at Escola Rural União, attended by Resex residents. To this end, a teaching plan was implemented with student involvement and participation from a problematic perspective, working in a contextualized way with traditional knowledge about vegetables. Thus, the final teaching plan entitled "Learning with the plants of the day to day" has a training character in order to contribute as a pedagogical tool for teachers to teach plant biology in a contextualized way and in approximation with the knowledge of the populations of the Forest. 


\section{INTRODUÇÃO}

O Programa de Mestrado Profissional em Ensino de Ciências e Matemática ofertado pela Universidade Federal do Acre tem como um dos objetivos formar professores que atuam na educação construindo um pensamento crítico sobre a prática docente sendo capaz de aperfeiçoar os métodos de ensino a partir de pesquisas aplicadas no ensino de Biologia, Química, Física e Matemática. Partido desse pressuposto foi proposto pelos professores do curso a elaboração de um produto educacional como resultado da pesquisa aplicada realizada durante o curso. Para iniciar o processo pensou-se em realizar uma investigação com as comunidades tradicionais, a escolhida foi a comunidade Rio Branco do Seringal Floresta da Reserva Extrativista (Resex) Chico Mendes, localizada no município de Xapuri/Acre. Este local corresponde a uma área utilizada e habitada por populações extrativistas tradicionais, cuja subsistência baseia-se em utilizar os recursos naturais e na criação de animais de pequeno porte.

A ideia de executar esse projeto surgiu do interesse em conhecer a diversidade vegetal presente na comunidade Rio Branco e propor ensinar os conhecimentos científicos sobre esse tema em aproximação com os conhecimentos da comunidade, permitindo, assim, o diálogo de saberes. A motivação em ensinar ciências na Escola Rural União foi despertada a partir da vivência das experiências com a comunidade, considerando que a Escola localizada na comunidade permite a troca de conhecimento e os seringueiros, moradores da Resex, é o público que frequenta a escola.

Nos últimos anos, ampliou-se a discussão sobre o ensino de Ciências, na perspectiva de que os processos de ensino e de aprendizagem sejam construídos em conjunto entre o professor e o aluno, e não como um processo unilateral onde o professor ensina e o aluno aprende. Baptista (2010) relata a importância de professores de Ciências promoverem o diálogo entre as concepções e ideias dos estudantes e o conhecimento científico sistematizado. Pomeroy (1994) afirma que se deve ensinar ciência por meio da diversidade cultural. Nessa perspectiva, introduzir a etnobotânica no ensino de Biologia pode despertar o sentimento de valorização cultural dos costumes regionais e desenvolver mentes criativas e participantes, mediante a apreensão do conhecimento científico.

A comunidade de estudo está localizada na Floresta Amazônica, reconhecidamente importante pela sua biodiversidade, em especial, no que diz respeito a espécies vegetais. Nosso futuro, o futuro do mundo e o futuro de todos os tipos de plantas dependem do nosso conhecimento e da capacidade em saber valorizar essa diversidade. 
Considerando que a Biologia Vegetal estuda as plantas, e que elas desempenham um importante papel para a sobrevivência biológica das comunidades humanas, tradicionais ou não, além de serem utilizadas em muitos campos de pesquisa cada vez mais relevantes para alguns problemas da sociedade, como o estudo de plantas medicinais e produção de fármacos, destaca-se a importância desse conteúdo estar inserido no currículo da Educação Básica.

Os moradores da comunidade em questão fazem uso das plantas presentes na floresta e de seu entorno para fins econômicos e de subsistência. Então, nada melhor do que ensinar conteúdos de Biologia Vegetal para quem convive diretamente com as plantas. Mediante o exposto, a questão de pesquisa que norteou este estudo foi: Como os conhecimentos tradicionais dos seringueiros podem ser utilizados em situações de ensino e aprendizagem de conteúdos de Biologia Vegetal na educação de jovens e adultos - EJA, da Escola Rural União, da Comunidade Rio Branco, Seringal Floresta da Resex Chico Mendes, no município de Xapuri/AC?

Para responder a questão proposta, buscou-se conhecer quais as espécies vegetais são utilizadas para fins econômicos e de subsistência pela comunidade Rio Branco, identificando as características de maneira a interpretá-las morfológica e fisiologicamente para ensinar Biologia Vegetal e assim elaborar e executar um plano de ensino com o tema "Biologia Vegetal: morfologia da folha e técnicas de coleta" aproximando os conhecimentos tradicionais do conhecimento científico transformando em saber escolar.

A proposta metodológica iniciou com o levantamento das espécies vegetais da Resex, utilizadas pela comunidade Rio Branco e sua utilização, e para tal houve a realização da pesquisa etnográfica que consta, essencialmente, de uma descrição de eventos que ocorrem no cotidiano da vida de um grupo, com especial atenção às estruturas sociais e às condutas dos indivíduos quanto ao seu status de organização ou princípios, e uma interpretação do que significa tudo isso para a cultura de um povo (MOREIRA, 2009). Ela também pode ser entendida como o estudo de um grupo ou povo (SILVEIRA, 2009). Assim, as espécies vegetais de uso cotidiano e de interesse econômico dos moradores do seringal Floresta foram conhecidas por meio do contato com a comunidade buscando vivenciar na prática a vida cotidiana do grupo. Para tal houve um percurso dentro da mata, nos caminhos percorridos diariamente pelos habitantes da comunidade. Nesta etapa houve a coleta de amostras dos vegetais mais utilizados e de interesse econômico e de subsistência para fins de elaboração de exsicatas. Em seguida, após a coleta, procedeu-se à fotodocumentação para enfatizar a disposição das folhas, flores/frutos e outras características que se perdem durante a coleta e secagem. As amostras foram secas em estufa, onde permaneceram durante dois dias e depois 
armazenadas no herbário da Universidade Federal do Acre- UFAC. Os dados coletados serviram como base para elaboração do plano de ensino, que foi elaborado a partir do texto etnográfico sobre os vegetais mais utilizados pela comunidade.

Na concepção de Freire (2013), a educação não deveria ensinar a repetir palavras ou se restringir a desenvolver a capacidade de pensá-las segundo as exigências lógicas do discurso abstrato. Deveria, sim, colocar o alfabetizado em condições de poder re-existenciar criticamente as palavras de seu mundo, para, na oportunidade devida, saber e poder dizer sua própria palavra.

A elaboração do plano de ensino aconteceu conforme a dinâmica abordada por Delizoicov e colaboradores (2011), que promoveram a transposição da concepção de educação freireana para o espaço da educação formal. Essa dinâmica é caracterizada por três momentos pedagógicos: 1. Problematização Inicial: quando se apresentam questões ou situações reais que os alunos conhecem e presenciam e que estão envolvidas nos temas. Nesse momento pedagógico, os alunos são desafiados a expor o que pensam sobre as situações, a fim de que o professor possa conhecer suas opiniões. Para os autores, a finalidade desse momento é propiciar um distanciamento crítico do aluno, ao fazer com que se defronte com as interpretações das situações propostas para discussão e que sinta a necessidade de adquirir outros conhecimentos que ainda não detém. 2. Organização do Conhecimento: momento em que, sob a orientação do professor, os conhecimentos do reino vegetal, necessários para a compreensão dos temas e da problematização inicial, são estudados. 3. Aplicação do Conhecimento: momento que se destina a abordar sistematicamente o conhecimento incorporado pelo aluno, para analisar e interpretar tanto as situações iniciais que determinaram seu estudo quanto outras que, embora não estejam diretamente ligadas ao momento inicial, possam ser compreendidas pelo mesmo conhecimento.

Desta forma, foi possível executar o plano de ensino que atendeu a um dos objetivos da pesquisa: o de aproximar o conhecimento tradicional do conhecimento científico, transformando em saberes escolares. Vale ressaltar a importância do planejamento de aula por meio da elaboração do plano de ensino, uma vez que essa ação antecede a organização do trabalho do professor em sala. Segundo Castro et al. (2008), a prática do professor deve estar aliada ao planejamento pedagógico, ou seja, a elaboração do plano de ensino deverá organizar e nortear o seu trabalho. É através dele que o professor perceberá a dimensão da importância e os objetivos de sua aula. O plano de ensino foi executado e desenvolvido na Escola Rural União, na turma da EJA, de maneira dialogada, a fim de que os alunos pudessem expressar suas opiniões e pontos de vista. No desenvolvimento das aulas, o plano de ensino foi sendo 
adequado para atender às demandas e necessidades dos estudantes de modo a contribuir com o processo de ensino e aprendizagem.

Os conteúdos abordados no plano de ensino contemplaram o componente curricular de Biologia, abordando a morfologia da folha, como também as técnicas para realizar uma coleta vegetal; a ideia foi o ser e o saber fazer de um biólogo. A confecção das exsicatas possibilitaria aos estudantes aprender como elaborá-las, como também entender como ocorre a identificação das espécies e da família dos vegetais que mais utilizam.

A troca de conhecimentos com os seringueiros evidenciou os saberes tradicionais oriundos da sua geração na qual eles utilizam para garantir sua sobrevivência na comunidade e aproximação do conhecimento científico é um passo importante para contribuir com a preservação do ambiente e conservação das espécies, fazendo que eles próprios possam reconhecer o espaço onde vivem, vivenciando de forma diferente o que costumam fazer diariamente. A partir dos resultados, percebeu-se que a pesquisa realizada teve boa aceitação pelos estudantes da Escola Rural União, desde a recepção até o final da aula, na qual declararam a motivação em aprender os conteúdos de Biologia Vegetal propostos. A aula realizada propôs momentos de aprendizagem que permitiram ensinar conteúdos de Biologia Vegetal, envolvendo a participação dos estudantes sob a perspectiva problematizadora, trabalhando de forma contextualizada com os saberes tradicionais sobre os vegetais. Freire (1986) afirma que a educação precisa desempenhar um papel importante na consciência dos educandos acerca da condição de suas vidas, a fim de lhes dar instrumentos para que possam compreender e perceber que é possível reconhecer-se como um ser transformador e atuante.

O produto educacional é o plano de ensino final intitulado "Aprendendo com as Plantas do dia a dia" que pode auxiliar docentes a ministrar conteúdos de Biologia Vegetal morfologia da folha de forma contextualizada e em aproximação com os conhecimentos das populações da Floresta acriana, com a utilização de textos, vídeos, atividades de campo e jogos para a fixação dos conteúdos, proporcionando uma forma mais prazerosa de aprender ciências.

A experiência na elaboração do plano de ensino teve um caráter de formação pois uma nova alternativa de metodologia foi criada para ensinar biologia vegetal aproximando os saberes da comunidade tradicional do conhecimento científico.

\section{REFERÊNCIAS BIBLIOGRÁFICAS}

BAPTISTA, G. C. S. Importância da demarcação de saberes no ensino de ciências para sociedades tradicionais. Ciência e Educação, v. 16, n. 3, p. 679-694, 2010. POMEROY, D. Science Education and Cultural Diversity: mapping the field. Studies in Science Education, 1994, p. 49-73. 
MOREIRA, M. A.; ROSA, P. R. S. Pesquisa em Ensino: Métodos Qualitativos e Quantitativos. Porto Alegre: Editora da UFRGS, 2009.

SILVEIRA, A. P.; FARIAS, C. C. Estudo Etnobotânico da Educação Básica. Poiésis Revista do Programa de Pós-Graduação em Educação, Tubarão, v. 2, n. 1, p. 14-31, jan/jun. 2009.

FREIRE, P. Pedagogia do Oprimido: saberes necessários a prática educativa. $54^{\mathrm{a}}$ ed. Rio de Janeiro: Paz e Terra, 2013.

CASTRO, P. A. P. P; TUNCUNDUVA, C. C.; ARNS, E. M. A importância do planejamento das aulas para organização do trabalho do professor em sua prática docente. Athena: Revista Cientifica de Educação, v. 10, n. 10, jan-jun. 2008. DELIZOICOV, D. Ensino de Ciências: Fundamentos e Métodos. São Paulo: Cortez Editora, 2011.

FREIRE, P.; SHOR, I. Medo e Ousadia. Rio de Janeiro: Paz e Terra, 1986.

\section{SOBRE A AUTORA:}

Mestre no Ensino de Ciências e Matemática. Professora de Biologia do Instituto Federal de Educação, Ciência e Tecnologia do Acre - IFAC, Campus Rio Branco. O artigo foi desenvolvido a partir das reflexões do estudo realizado para obtenção da dissertação de mestrado da autora "Ensinando Biologia Vegetal a partir do conhecimento tradicional de seringueiros do Seringal Floresta da Resex Chico Mendes" defendida no ano de 2017 no Programa de Pós-Graduação no Ensino de Ciências e Matemática ofertado pela UFAC. 